PUBLIC HEALTH

\title{
Violence against wives, sexual risk and sexually transmitted infection among Bangladeshi men
}

\author{
Jay G Silverman, Michele R Decker, Nitin A Kapur, Jhumka Gupta, Anita Raj
}

See linked editorial, p173

Sex Transm Infect 2007;83:211-215. doi: 10.1136/sti.2006.023366

See end of article for authors' affiliations .....................

Correspondence to: Dr J G Silverman, Department of Society, Human Development and Health, Harvard School of Public Health, 677 Huntington Avenue, Boston, MA 02115, USA; jsilverm@ hsph.harvard.edu

Accepted 23 January 2007

\begin{abstract}
Objective: To assess the relationship between men's reported violence against wives and their sexual risk behaviours and sexual health.

Design, setting and participants: Cross-sectional analyses of a survey of a nationally representative household-based sample of married men in Bangladesh $(n=3096)$.

Main outcome measure(s): Physical and sexual violence against wives during the previous 12 months was assessed and examined for relations to men's extramarital sexual behaviours and sexually transmitted infection (STI) symptoms or diagnosis during this same period, as well as to men's disclosure of such infection to wives and condom use while infected.

Results: More than 1 in 3 (36.84\%) married Bangladeshi men reported physically and/or sexually abusing their wives in the past year. Men perpetrating such violence were more likely to report both premarital and extramarital sex partners $\left(\mathrm{OR}_{\mathrm{adj}} \mathrm{s} 1.80-3.45 ; 95 \% \mathrm{Cl} 1.20\right.$ to 8.23); those reporting physical violence were more likely to report STI symptoms or diagnosis in the past year $\left(\mathrm{OR}_{\mathrm{adj}} \mathrm{s} 1.68-2.52 ; 95 \% \mathrm{Cl} 1.24\right.$ to 3.73$)$. Men perpetrating physical violence and contracting an STI were somewhat more likely to fail to disclose infection status to wives $\left(\mathrm{OR}_{\mathrm{adj}} 1.58 ; 95 \% \mathrm{Cl} 0.93\right.$ to 2.70$)$ than infected men not reporting such abuse.

Conclusions: Violence against wives is common among Bangladeshi men. Men who perpetrate such abuse represent increased risk regarding their wives' sexual health because they are more likely to both participate in extramarital sexual behaviour and contract an STI compared with non-abusive husbands. Given the growing epidemic of HIV infection among monogamous South Asian women based on intercourse with infected non-monogamous husbands, research and intervention regarding men's violence in marriage and implications of such behaviour for women's sexual health should be prioritised.
\end{abstract}

ntimate partner violence (IPV) is widely recognised as a global public health concern, with immediate and long-term consequences to women including injury, psychological distress and compromised sexual health. ${ }^{1-4}$ of tremendous recent concern is consistent evidence demonstrating an increased risk of contracting HIV/AIDS and other sexually transmitted infections (STIs) among women experiencing IPV. ${ }^{15-8}$ Diminished control over sexual protection evidenced among women who are abused ${ }^{9-11}$ may partially explain these associations. However, evidence of increased rates of sexual risk behaviour (eg, extramarital and multiple sex partnering, no or inconsistent condom use and forced unprotected sex $)^{12-17}$ among male perpetrators of IPV indicates the need for investigations into the associations of men's abusive and sexual risk behaviours as potentially compromising both their own sexual health as well as that of their female partners.

Advancing knowledge of this topic is of particularly grave importance in South Asia given recent evidence indicating rapid increases in HIV infection rates among married monogamous women in this region for whom husbands represent the only source of infection. ${ }^{18-21}$ Although high rates of IPV victimisation have been documented among multiple samples of Indian and Bangladeshi women, ${ }^{1}{ }^{22-28}$ little research has been conducted on either partner violence perpetration among South Asian men or the relationship of such abusive behaviours with men's sexual risk behaviours, sexual health outcomes and the sexual health risks posed to the wives of such men.

The single study integrating these issues among South Asian men identified an association of IPV perpetration and men's STI symptoms among a state-wide sample of Indian men; notably, this association was strongest among those men reporting sexual violence against their wives. ${ }^{15}$ This study seeks to build on this previous work by utilising a large nationally representative Bangladeshi sample to investigate men's selfreported physical and sexual violence perpetration against their wives in relation to their extramarital sexual behaviour, STI diagnoses and symptoms, disclosure of STI status to wives and sexual protection after STI.

\section{METHODS}

Sample

This study used the 2004 MEASURE Bangladesh Demographic Health Survey, conducted by the National Institute for Population Research and Training of the Ministry of Health and Family Welfare of Bangladesh from January to May 2004. The survey used a nation-wide sample drawn from all individuals residing in private dwellings. A stratified, multistage cluster sample of 361 primary sampling units, 122 in the urban area and 239 in the rural area, was constructed. After the sample list for the women's questionnaire was developed, 50\% of selected households were targeted as sites for the men's questionnaire. One man, married or not married, between 15 and 54 years of age was chosen at random from each of the households on the sample list. Of 4490 eligible men identified, 4297 completed questionnaires, resulting in a $95.7 \%$ participation rate. Details of data collection and management procedures are described elsewhere. ${ }^{29}$ Of the 4297 participants, 1166 were excluded from the current sample because they were not married and, as such, were not asked about IPV perpetration; an additional 35 participants were not currently living with their wives, resulting in a final sample size of 3096.

Abbreviations: IPV, intimate partner violence; STI, sexually transmitted infection 


\section{Measures}

The questionnaires were drafted in English and then translated into Bangla, the national language of Bangladesh. Questionnaires were administered verbally through a trained interviewer to minimise potential literacy barriers. All variables were assessed via self-report. Demographics including age, education, polygamy and religion were assessed via single items. A relative index of household wealth was calculated based on interviewer-observed assets including ownership of consumer items and dwelling characteristics; individuals were ranked on the basis of their household score and divided into quintiles with 1 being the poorest and 5 the wealthiest $20 \%$ of households.

IPV perpetration was assessed through 6 items pertaining to past-year perpetration of violence against wives. A positive answer to any one of the following behaviours during the past year indicated physical IPV perpetration: "pushing or shaking your wife or throwing something at her", "slapping her or twisting her arm", "punching her with your fist or something that could hurt her", "kicking her or dragging her", or "trying to strangle her or kill her by burning her". A positive answer to "physically forcing her to have sexual intercourse even when she didn't want to" in the past year indicated sexual IPV perpetration. These assessments were recoded to create a fourlevel categorical variable reflecting three categories of past-year IPV perpetration (ie, physical IPV only, sexual IPV only and both physical and sexual IPV perpetration during the past year) with no IPV perpetration in the past year as the referent group.

Single items assessed men's participation in extramarital (both ever and within the past year) and premarital sexual relationships with women. Respondents were classified as having had a past-year STI if they indicated any of the following three symptoms within the past year- "discharge from your penis", "a sore or ulcer on or near your penis" or "pain or burning sensation during urination"—or if they indicated that they had been diagnosed with an STI within the past year. Respondents reporting past-year STI were asked to recall the last period in which they had symptoms or were diagnosed with such an infection and indicate whether they had informed their wife of the infection, and whether they had sex with anyone (including their wife) during this time. Respondents indicating that they had been sexually active when they last had symptoms or were diagnosed with an STI were asked to report whether they had used a condom the last time they had sex under these circumstances, and whether they had used a condom every time they had sex during the infection; those indicating that they had not used a condom either during the last time they had sex or during any other sexual encounter under these circumstances were coded as having not used a condom while infected with an STI.

\section{Analysis}

Prevalence estimates of past-year physical IPV only, sexual IPV only, both physical and sexual IPV and any form of IPV were calculated for the total sample of married Bangladeshi men and by demographics. Demographic differences in IPV perpetration were assessed by $\chi^{2}$ analyses; significance for all analyses was set at $\mathrm{p}<0.05$. Adjusted logistic regression models were constructed to estimate odds ratios (OR) and 95\% confidence intervals (CI) for the association of each category of IPV perpetration with extramarital sexual behaviours and sexual health outcomes assessed using respondents indicating no pastyear IPV perpetration as the referent group. Potential confounders of associations included in regression models included age, rural/urban residence, education, wealth, religion and polygamy (simultaneous marriage to more than one wife). In accordance with procedures recommended by Rothman and
Greenland, ${ }^{30}$ variables that either altered crude point estimates $>10 \%$ or were significant predictors at $\alpha=0.20$ were included in adjusted models. As all categories of IPV perpetration were assessed within a single regression model for each sexual health outcome, potential confounders of the association of all categories of IPV perpetration are identical for each outcome assessed. All statistical analysis was conducted using STATA V.9 so as to appropriately consider sample weighting based on the complex sampling design of the Bangladesh Demographic Health Survey.

\section{RESULTS \\ Past-year prevalence of IPV perpetration and demographic associations}

Over one-third (36.84\%) of Bangladeshi married men reported perpetrating some form of violence against their wives within the past year. Approximately 1 in $5(19.56 \%)$ men reported perpetrating physical violence in the absence of sexual violence while 1 in $10(9.52 \%)$ reported perpetrating only sexual violence and slightly less than 1 in $13(7.76 \%)$ reported perpetration of both physical and sexual IPV within the past year (table 1).

$\chi^{2}$ analyses revealed several significant differences in the prevalence of IPV perpetration across demographic groups. Specifically, younger men were more likely to report perpetration of all forms of IPV in the past year compared with older men, and men reporting higher levels of education were less likely to report perpetration of physical IPV, both alone and in combination with sexual IPV, compared with men reporting having received less education (as evidenced by non-overlapping CIs for the youngest/lowest and oldest/highest categories of age and education). Although the trend regarding the relationship between education and sexual IPV without physical IPV perpetration is less clear, men completing secondary education were more likely to report sexual IPV only in the past year compared with those men who reported receiving no education ( $13.47 \%$ vs $7.05 \%)$. Across wealth categories, wealthier married men were less likely to report past-year perpetration of any form of IPV and past-year perpetration of both physical and sexual IPV but not of either physical or sexual violence alone. A higher prevalence of perpetration of any form of IPV in the past year was identified among Muslim as compared with Hindu married Bangladeshi men, but these differences were not significant for the three mutually exclusive categories of violence assessed.

\section{Relationship between past-year IPV perpetration and sexual risk behaviours and STI}

In logistic regression analyses adjusted for demographics meeting criteria for potential confounding, Bangladeshi men who reported perpetration of physical but not sexual IPV in the past year were more likely to report multiple forms of sexual risk behaviour, including having engaged in premarital sex $\left(\mathrm{OR}_{\mathrm{adj}} 1.80,95 \% \mathrm{CI} 1.37\right.$ to 2.36$)$ and extramarital sex ever (i.e., during marriage, $\mathrm{OR}_{\mathrm{adj}} 1.90,95 \%$ CI 1.26 to 2.88 ). These men were also at increased risk of past-year STI symptoms or diagnosis $\left(\mathrm{OR}_{\mathrm{adj}} 1.68,95 \% \mathrm{CI} 1.24\right.$ to 2.26$)$. Men reporting pastyear IPV perpetration that was sexual but not physical in nature were at increased risk of having engaged in premarital sex $\left(\mathrm{OR}_{\mathrm{adj}} 2.33,95 \% \mathrm{CI} 1.72\right.$ to 3.16$)$ and extramarital sex ever $\left(\mathrm{OR}_{\mathrm{adj}} 2.53,95 \%\right.$ CI 1.49 to 4.31$)$; a possible association with increased risk of STI symptoms or diagnosis in the past year was detected $\left(\mathrm{OR}_{\mathrm{adj}} 1.46,95 \% \mathrm{CI} 0.95\right.$ to 2.24$)$ based on such perpetration, but this association did not reach statistical significance. Finally, men reporting perpetrating both physical and sexual IPV in the past year were more likely to report premarital sex $\left(\mathrm{OR}_{\mathrm{adj}} 2.76,95 \% \mathrm{CI} 1.90\right.$ to 4.03$)$, extramarital sex both ever $\left(\mathrm{OR}_{\text {adj }} 2.05,95 \%\right.$ CI 1.20 to 3.49$)$ and within the 
Table 1 Demographic characteristics of married Bangladeshi men $(n=3096)$ and associations with forms of past-year intimate partner violence (IPV) perpetration

\begin{tabular}{|c|c|c|c|c|c|}
\hline & Sample \% (95\% Cl) & Any form of IPV (past year) & $\begin{array}{l}\text { Physical IPV only (past } \\
\text { year) }\end{array}$ & $\begin{array}{l}\text { Sexual IPV only (past } \\
\text { year) }\end{array}$ & $\begin{array}{l}\text { Both physical and sexual } \\
\text { IPV (past year) }\end{array}$ \\
\hline $\begin{array}{l}\text { Age (years) } \\
15-25 \\
26-35 \\
36-45 \\
46-55 \\
\text { p Value }\end{array}$ & $\begin{array}{l}11.95 \text { (10.67 to } 13.36) \\
32.05 \text { (29.98 to } 34.19) \\
36.06 \text { (34.31 to } 37.85) \\
19.94 \text { (18.23 to } 21.77)\end{array}$ & $\begin{array}{l}58.54 \text { (53.07 to } 63.81) \\
45.57 \text { (41.62 to } 49.58) \\
30.12 \text { (26.85 to } 33.61) \\
21.96 \text { (18.23 to } 26.20) \\
<0.001\end{array}$ & $\begin{array}{l}28.90(24.20 \text { to } 34.10) \\
21.60(18.68 \text { to } 24.84) \\
17.74(15.25 \text { to } 20.53) \\
14.01(11.22 \text { to } 17.36) \\
<0.001\end{array}$ & $\begin{array}{l}12.03(8.19 \text { to } 17.35) \\
13.22(10.95 \text { to } 15.87) \\
7.23(5.64 \text { to } 9.22) \\
6.21(4.04 \text { to } 9.45) \\
<0.001\end{array}$ & $\begin{array}{l}17.61(13.17 \text { to } 23.16) \\
10.76(8.76 \text { to } 13.16) \\
5.16(3.96 \text { to } 6.70) \\
1.74(0.63 \text { to } 9.07) \\
<0.001\end{array}$ \\
\hline $\begin{array}{l}\text { Residence } \\
\text { Urban } \\
\text { Rural } \\
\text { p Value }\end{array}$ & $\begin{array}{l}23.32(21.61 \text { to } 25.12) \\
76.68 \text { (74.88 to } 78.39)\end{array}$ & $\begin{array}{l}36.89(31.54 \text { to } 42.57) \\
36.83(34.23 \text { to } 39.51) \\
0.985\end{array}$ & $\begin{array}{l}21.16(17.40 \text { to } 25.48) \\
19.08 \text { (17.25 to } 21.06) \\
0.365\end{array}$ & $\begin{array}{l}9.79(7.48 \text { to } 12.71) \\
9.44(7.99 \text { to } 11.11) \\
0.818\end{array}$ & $\begin{array}{l}5.94(4.25 \text { to } 8.24) \\
8.31 \text { (6.95 to } 9.91) \\
0.057\end{array}$ \\
\hline $\begin{array}{l}\text { Education } \\
\text { No education } \\
\text { Primary } \\
\text { Secondary } \\
\text { Higher } \\
\text { p Value }\end{array}$ & $\begin{array}{l}31.00 \text { (28.57 to } 33.54) \\
37.52 \text { (35.51 to } 39.58) \\
21.45(19.69 \text { to } 23.33) \\
10.02 \text { (8.79 to } 11.40)\end{array}$ & $\begin{array}{l}39.83(35.98 \text { to } 43.82) \\
40.38 \text { (36.60 to } 43.82) \\
32.39 \text { (27.68 to } 37.49) \\
23.86 \text { (17.95 to } 30.97) \\
<0.001\end{array}$ & $\begin{array}{l}24.07(20.93 \text { to } 27.52) \\
21.15(18.43 \text { to } 24.16) \\
13.40(10.50 \text { to } 16.96) \\
12.85(8.82 \text { to } 18.35) \\
<0.001\end{array}$ & $\begin{array}{l}7.05(5.42 \text { to } 9.12) \\
9.38(7.53 \text { to } 11.64) \\
13.47(10.21 \text { to } 17.57) \\
9.22(5.56 \text { to } 14.89) \\
0.004\end{array}$ & $\begin{array}{l}8.71(6.53 \text { to } 11.55) \\
9.84(8.13 \text { to } 11.87) \\
5.52(3.78 \text { to } 8.00) \\
1.79(0.79 \text { to } 4.03) \\
<0.001\end{array}$ \\
\hline $\begin{array}{l}\text { Wealth index } \\
\text { Poorest } \\
\text { Poorer } \\
\text { Middle } \\
\text { Richer } \\
\text { Richest } \\
\text { p Value }\end{array}$ & $\begin{array}{l}19.92(17.86 \text { to } 22.15) \\
21.46(19.64 \text { to } 23.40) \\
20.09 \text { (18.17 to } 22.16) \\
18.83(16.94 \text { to } 20.88) \\
19.69 \text { (17.60 to } 21.97)\end{array}$ & $\begin{array}{l}40.93(35.88 \text { to } 46.17) \\
41.0(36.62 \text { to } 45.53) \\
40.72 \text { (36.05 to } 45.57) \\
31.68 \text { (26.61 to } 37.22) \\
29.15(23.55 \text { to } 35.47) \\
<0.001\end{array}$ & $\begin{array}{l}21.92(18.58 \text { to } 25.67) \\
22.75(19.16 \text { to } 26.8) \\
18.92(15.4 \text { to } 22.99) \\
18.38(14.62 \text { to } 22.85) \\
15.50(11.94 \text { to } 19.88) \\
0.066\end{array}$ & $\begin{array}{l}7.92(5.84 \text { to } 10.65) \\
9.61(7.60 \text { to } 12.07) \\
10.77(7.84 \text { to } 14.63) \\
8.42(5.79 \text { to } 12.11) \\
10.80(7.92 \text { to } 14.57) \\
0.593\end{array}$ & $\begin{array}{l}11.09(8.43,14.45) \\
8.64(6.36 \text { to } 11.64) \\
11.04(8.03 \text { to } 14.99) \\
4.88(3.16 \text { to } 7.44) \\
2.85(1.70 \text { to } 4.73) \\
<0.001\end{array}$ \\
\hline $\begin{array}{l}\text { Religion } \\
\text { Muslim } \\
\text { Hindu } \\
\text { p Value }\end{array}$ & $\begin{array}{c}90.04(86.71 \text { to } 92.60) \\
9.96(7.40 \text { to } 13.29)\end{array}$ & $\begin{array}{l}37.84(35.43 \text { to } 40.32) \\
27.71 \text { (21.70 to } 34.65) \\
0.008\end{array}$ & $\begin{array}{l}20.00(18.23 \text { to } 21.9) \\
15.08 \text { (10.74 to } 20.76) \\
0.086\end{array}$ & $\begin{array}{l}9.92(8.56 \text { to } 11.47) \\
6.75(4.10 \text { to } 10.92) \\
0.119\end{array}$ & $\begin{array}{l}7.92(6.72 \text { to } 9.32) \\
5.88 \text { (3.10 to } 10.85) \\
0.296\end{array}$ \\
\hline $\begin{array}{l}\text { Number of wives } \\
\text { One } \\
\text { More than one } \\
p \text { Value }\end{array}$ & $\begin{array}{c}95.38 \text { (93.84 to } 96.55) \\
4.62 \text { (3.45 to } 6.12)\end{array}$ & $\begin{array}{l}36.78(34.29 \text { to } 39.33) \\
38.18(28.57 \text { to } 48.81) \\
0.797\end{array}$ & $\begin{array}{l}22.16(15.07 \text { to } 31.35) \\
19.44 \text { (17.66 to } 21.35) \\
0.531\end{array}$ & $\begin{array}{l}10.22(5.47 \text { to } 18.3) \\
9.48(8.22 \text { to } 10.92) \\
0.817\end{array}$ & $\begin{array}{l}7.85(6.67 \text { to } 9.23) \\
5.80(2.93 \text { to } 11.16) \\
0.338\end{array}$ \\
\hline Total & 3096 & 36.84 (34.37 to 39.28 ) & 19.56 (17.88 to 21.37$)$ & 9.52 (8.26 to 10.94$)$ & 7.76 (6.63 to 9.07 ) \\
\hline
\end{tabular}

past year $\left(\mathrm{OR}_{\mathrm{adj}} 3.45,95 \%\right.$ CI 1.45 to 8.23$)$, and past-year STI symptoms and/or diagnosis $\left(\mathrm{OR}_{\mathrm{adj}} 2.52,95 \% \mathrm{CI} 1.71\right.$ to 3.73$)$ (table 2).
Among men reporting STI symptoms or diagnosis in the past year, a trend not reaching statistical significance was detected between perpetration of physical IPV and non-disclosure of STI

Table 2 Associations of forms of past-year intimate partner violence perpetration with extramarital sexual behaviours, sexually transmitted infection (STI) symptoms and/or diagnosis, STI disclosure and condom use during recent STI among married Bangladeshi men $(n=3096)$

\begin{tabular}{|c|c|c|c|c|c|}
\hline & $\begin{array}{l}\text { Any form of IPV } \\
\%(95 \% \mathrm{Cl})\end{array}$ & $\begin{array}{l}\text { No IPV } \\
\%(95 \% \mathrm{Cl})\end{array}$ & $\begin{array}{l}\text { Perpetrated } \\
\text { physical IPV only } \\
\text { OR }(95 \% \mathrm{Cl})\end{array}$ & $\begin{array}{l}\text { Perpetrated } \\
\text { sexual IPV only } \\
\text { OR }(95 \% \mathrm{CI})\end{array}$ & $\begin{array}{l}\text { Perpetrated both } \\
\text { physical and } \\
\text { sexual IPV } \\
\text { OR }(95 \% \mathrm{CI})\end{array}$ \\
\hline Premarital sex* & 34.14 (31.13 to 37.28$)$ & 19.36 (16.92 to 22.06$)$ & 1.80 (1.37 to 2.36$)$ & 2.33 (1.72 to 3.16$)$ & 2.76 (1.90 to 4.03$)$ \\
\hline Extramarital sex, ever† & 8.69 (7.0 to 10.80$)$ & 4.25 (3.32 to 5.43$)$ & 1.90 (1.26 to 2.88$)$ & 2.53 (1.49 to 4.31$)$ & 2.05 (1.20 to 3.49$)$ \\
\hline Extramarital sex, past yearł & $2.39(1.57$ to 3.64$)$ & $0.94(0.56$ to 1.56$)$ & $2.01(0.88$ to 4.60$)$ & $1.04(0.33$ to 3.31$)$ & $3.45(1.45$ to 8.23$)$ \\
\hline $\begin{array}{l}\text { STI symptoms/diagnosis, past } \\
\text { year§ }\end{array}$ & 23.05 (19.92 to 26.51$)$ & $13.43(11.41$ to 15.75$)$ & $1.68(1.24$ to 2.26$)$ & $1.46(0.95$ to 2.24$)$ & $2.52(1.71$ to 3.73$)$ \\
\hline $\begin{array}{l}\text { Non-disclosure of most } \\
\text { recent } \mathrm{STI} \boldsymbol{\Phi}^{* *}\end{array}$ & $37.07(30.50$ to 44.14$)$ & 31.71 (24.63 to 39.75$)$ & $1.58(0.93$ to 2.70$)$ & $0.79(0.37$ to 1.71$)$ & $0.88(0.45$ to 1.73$)$ \\
\hline 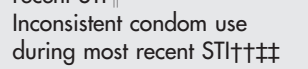 & 81.67 (69.99 to 89.49$)$ & 78.82 (64.78 to 88.27$)$ & $0.84(0.31$ to 2.33$)$ & $2.22(0.28$ to 17.61$)$ & $2.72(0.61$ to 12.15$)$ \\
\hline
\end{tabular}

*Analyses adjusted for age and education.

†Analyses adjusted for education, wealth and number of wives.

$\ddagger$ Analyses adjusted for age and religion.

$\S$ Analyses adjusted for education, wealth, rural/urban, number of wives, and religion.

-Analyses adjusted for age and rural/urban.

${ }^{* *}$ Among those reporting past-year STI $(n=511)$.

$\dagger †$ Analyses adjusted for age, wealth, and rural/urban.

†¥Among those reporting having had sex during their last STI $(n=159)$. 
to wives $\left(\mathrm{OR}_{\mathrm{adj}} 1.58,95 \% \mathrm{CI} 0.93\right.$ to 2.70$)$; no other associations were detected between IPV perpetration and STI disclosure behaviour. Further, no associations were identified between past-year IPV perpetration and failure to use condoms with a sexual partner during the period when last experiencing STI symptoms or receiving an STI diagnosis.

\section{DISCUSSION}

Findings from this first nationally-representative examination of men's perpetration of IPV and their sexual health indicate that more than one in three married men in Bangladesh reported physically or sexually abusing their wives in the past year. This result is consistent with previous studies based on women's reports conducted in both urban and rural Bangladesh demonstrating similarly high rates of IPV. ${ }^{12-25}$ These findings also demonstrate that men reporting perpetration of IPV in the past year are more likely to engage in extramarital sexual behaviour and are at significantly increased risk for recent STI symptoms/diagnosis. These findings are consistent with those from a large study of married men from a rural northern Indian state that demonstrated associations of lifetime IPV perpetration with both premarital and extramarital sex, as well as STI symptoms. ${ }^{15}$

Notably, current findings of associations between sexual risk and IPV perpetration are also consistent with multiple prior studies conducted in a diversity of international settings outside South Asia (eg, the USA and South Africa). ${ }^{16}{ }^{17}$ Thus, the implications of the current findings may extend beyond the South Asian context and inform a growing global body of evidence linking perpetration of gender-based violence with men's sexual risk behaviour. Primary among such implications is the need for inclusion of IPV and other forms of gender-based violence within sexual health promotion and STI/HIV prevention efforts conducted among both men and women.

New to this body of work, IPV perpetration in the past year was associated with both past-year extramarital sex (for IPV reported as both physical and sexual) and past-year STI (for physical IPV with or without sexual IPV), indicating potential concurrency of men's violence against wives and their extramarital sexual behaviour and related infection. This concurrency indicates a compounding of the danger faced by abused wives in that, beyond the injury and non-sexual health risks directly related to victimisation through physical and sexual violence, their sexual and reproductive health may be compromised on the basis of their husbands' sexual risk behaviours and STIs. The sexual risk behaviours of men who perpetrate violence against their partners have been posited to underpin the associations consistently demonstrated between women's violence victimisation and their increased risk for STI, including HIV/AIDS. ${ }^{31} 32$ Present analyses support this hypothesis by providing evidence that perpetrators of recent IPV are more likely to engage in recent risky sexual behaviours and recently contract STIs compared with men not perpetrating IPV. These findings, coupled with the documented limited sexual negotiation power (ie, the capacity to refuse sexual activity, or to insist on condom use or other protection) among women who are physically abused by their male partners, ${ }^{9-11}$ present a clear pathway for abused women's sexual risk.

South Asian cultural norms have been described as limiting communication concerning sexual health among married couples. ${ }^{10}$ Men reporting past-year physical IPV in this study were more likely to not disclose this infection to their spouse than other men who had contracted an STI, although this finding did not reach statistical significance. This finding indicates a possible further compounding of the risk abusive men pose to their wives' sexual health, in that such men are more likely to contract an STI and to, perhaps, not disclose the infection, thus inhibiting their wives' ability to make informed choices regarding sexual protection. Previous research has documented fear of partner violence as a primary reason for women choosing not to disclose their HIV serostatus to sexual partners, ${ }^{33-36}$ but the present findings represent the first assessment of the role of IPV perpetration in men's disclosure of STI/HIV status to their partners. Given the growing epidemic of HIV infection among monogamous South Asian women who have intercourse with infected multiple-partnering husbands, ${ }^{21}$ research into the issues of violence and coercion in such relationships and how this relates to men's disclosure of STIs and other aspects of women's ability to protect themselves should be considered a high priority. Future research should examine this relationship in greater depth with a broader array of disclosure outcomes including women's reports of such communication.

These findings should be considered in the light of several design limitations. Cross-sectional analyses do not allow us to determine the relative chronology of extramarital sexual behaviours and STI symptoms/diagnosis in relation to IPV perpetration within the past-year timeframe assessed. Longitudinal and qualitative research is needed to clarify the causal and temporal relationships between IPV and sexual risk and sexual health. All instances of premarital sexual behaviour may not represent partnering with women other than wivesthat is, men may report having had premarital sex with women they later married. Thus, such behaviour, in itself, would not confer sexual risk. Although the syndromic approach to STI diagnosis such as the assessment currently used is recommended for settings that lack diagnostic facilities, ${ }^{37}$ the underreporting of STI may have occurred on the basis of not receiving formal STI diagnosis or lack of familiarity with the STI symptoms assessed. Such under-reporting and resulting misclassification of STI status may have biased results in the direction of the null, thus underestimating associations of STI and IPV. Conversely, symptoms listed as indicative of STI may not definitely indicate such infection (eg, painful urination based on prostate enlargement). Notably, other critically important sexual risk behaviours (eg, frequency of condom use with wives and extramarital partners) were not available for consideration as outcomes or confounders in the present analyses. Analyses concerning inconsistent condom use during last STI and disclosure of STI to spouse faced limited statistical power given the reduced sample size used for these analyses. Finally, although this sample is nationally representative of married Bangladeshi men residing in private dwellings, it is unclear to what extent these findings may generalise to men living in other types of housing or those of other nationalities and cultures.

\section{Key messages}

- More than 1 in $3(36.8 \%)$ married Bangladeshi men reported physically and/or sexually abusing their wives in the past year.

- Bangladeshi men who perpetrate intimate partner violence represent a greater threat to the sexual health of their wives compared with non-abusive men, based on increased rates of extramarital sexual behaviour and acquisition of STI.

- Given the growing epidemic of heterosexual HIV infection among monogamous South Asian women, research and intervention regarding men's violence in marriage and implications of such behaviour for women's sexual health should be prioritised. 
The findings clearly demonstrate a high level of IPV perpetration among married Bangladeshi men, with more than 1 in 3 reporting having physically and/or sexually abused their wives in the past year, and increased rates of both extramarital sex and STI symptoms/diagnoses during this same period among men perpetrating such abuse. Given the stigma and severe social and economic costs associated with divorce and separation in Bangladesh; ${ }^{23}$ low levels of help-seeking for IPV among Bangladeshi women who are abused, ${ }^{24}$ cultural norms dictating low levels of communication between spouses concerning sexuality and diminished sexual negotiating power among women ${ }^{10}$ who are abused; and the present findings of greater risk for STI presented by abusive married men should serve to emphasise the great need for intervention to both prevent and intervene in men's violence against their wives and better assist women physically and sexually victimised by their husbands. Such prevention and intervention may be critical not only for preventing the direct and injurious consequences of IPV, but also for protecting women from STIs, including HIV.

\section{AUTHOR CONTRIBUTIONS}

JGS led conceptualisation and writing; MRD assisted with conceptualisation, data analyses and writing; NAK led data analyses; JG assisted in data analyses and writing; AR co-led conceptualisation and assisted in writing.

\section{Authors' affiliations \\ Jay G Silverman, Michele R Decker, Nitin A Kapur, Jhumka Gupta,}

Department of Society, Human Development and Health, Harvard School of Public Health, Boston, Massachusetts, USA

Anita Raj, Department of Social and Behavioral Sciences, Boston University School of Public Health, Boston, Massachusetts, USA

Competing interests: None declared.

Approval by the Harvard School of Public Health Ethical Review Board was not required based on the conduct of secondary data analyses devoid of personal identifiers.

\section{REFERENCES}

1 Salam MA, Alim MA, Noguchi T. Spousal abuse against women and its consequences on reproductive health: a study in the urban slums in Bangladesh. Matern Child Health J 2006; 10:83-94.

2 Panchanadeswaran S, Koverola C. The voices of battered women in India. Violence Against Women 2005;11:736-58.

3 Patel V, Kirkwood BR, Weiss $\mathrm{H}$, et al. Chronic fatigue in developing countries: population based survey of women in India. BMJ 2005;330:1190.

4 Kumar S, Jeyaseelan L, Suresh S, et al. Domestic violence and its mental health correlates in Indian women. Br J Psychiatry 2005;187:62-7.

5 Decker MR, Silverman JG, Raj A. Dating violence and sexually transmitted disease/HIV testing and diagnosis among adolescent females. Pediatrics 2005; 116:e272-6.

6 Dunkle KL, Jewkes RK, Brown HC, et al. Gender-based violence, relationship power, and risk of HIV infection in women attending antenatal clinics in South Africa. Lancet 2004;363:1415-21.

7 El-Bassel N, Gilbert L, Wu E, et al. HIV and intimate partner violence among methadone-maintained women in New York City. Soc Sci Med 2005:61:171-83.

8 Wingood GM, DiClemente RJ, Raj A. Adverse consequences of intimate partner abuse among women in non-urban domestic violence shelters. Am J Prev Med 2000; 19:270-5.

9 Go VF, Sethulakshmi CJ, Bentley ME, et al. When HIV-prevention messages and gender norms clash: the impact of domestic violence on women's HIV risk in the slums of Chennai, India. AIDS Behav 2003;7:263-72.
10 Sivaram S, Johnson S, Bentley ME, et al. Sexual health promotion in Chennai, India: key role of communication among social networks. Health Promot Intern 2005;20:327-33

11 Wingood GM, DiClemente RJ. The effects of an abusive primary partner on the condom use and sexual negotiation practices of African-American women. Am J Public Health 1997;87:1016-18.

12 Eby KK, Campbell JC, Sullivan CM, et al. Health effects of experiences of sexual violence for women with abusive partners. Health Care Women Int 1995; 16:563-76.

13 El-Bassel N, Fontdevila J, Gilbert L, et al. HIV risks of men in methadone maintenance treatment programs who abuse their intimate partners: a forgotten issue. J Subst Abuse 2001;13:29-43.

14 Peedicayil A, Sadowski LS, Jeyaseelan L, et al. Spousal physical violence against women during pregnancy. BJOG 2004;111:682-7.

15 Martin SL, Kilgallen B, Tsui AO, et al. Sexual behaviors and reproductive health outcomes: associations with wife abuse in India. JAMA 1999;282:1967-72.

16 Raj A, Santana C, La Marche A, et al. Perpetration of partner violence associated with sexual risk behaviors among young adult men. Am J Public Health 2006;96:1873-8.

17 Dunkle KL, Jewkes RK, Nduna M, et al. Perpetration of partner violence and HIV risk behaviour among young men in the rural Eastern Cape, South Africa. AIDS 2006;20:2107-14.

18 Gangakhedkar RR, Bentley ME, Divekar AD, et al. Spread of HIV infection in married monogamous women in India. JAMA 1997;278:2090-2.

19 Mehta SH, Gupta A, Sahay S, et al. High HIV prevalence among a high-risk subgroup of women attending sexually transmitted infection clinics in Pune, India. J Acquir Immune Defic Syndr 2006;41:75-80.

20 Newmann S, Sarin P, PKumarasamy N, et al. Marriage, monogamy and HIV: a profile of HIV-infected women in south India. Int J STD AIDS 2000;1 1:250-3.

21 United Nations Development Program. Gender impact of HIV and AIDS in India. New Delhi: United Nations Development Program, 2006.

22 Bates LM, Schuler SR, Islam F, et al. Socioeconomic factors and processes associated wtih domestic violence in rural Bangladesh. Int Fam Plann Perspect 2004;30:190-9.

23 Bhuiya A, Sharmin T, Hanifi SMA. Nature of domestic violence against women in a rural area of Bangladesh: implication for preventive interventions. J Health Popul Nutr 2003;21:48-54.

24 Naved RT, Azim S, Bhuiya A, et al. Physical violence by husbands: magnitude, disclosure and help-seeking behavior of women in Bangladesh. Soc Sci Med Jan 19, 2006;62:2917-29

25 Koenig MA, Ahmed S, Hossain MB, et al. Women's status and domestic violence in rural Bangladesh: individual and community-level effects. Demography 2003;40:269-88

26 Jain D, Sanon S, Sadowski L, et al. Violence against women in India: evidence from rural Maharashtra, India. Rural Remote Health 2004;4:304.

27 Koenig MA, Stephenson R, Ahmed S, et al. Individual and contextual determinants of domestic violence in North India. Am J Public Health 2006;96:132-8.

28 Krishnan S. Gender, caste, and economic inequalities and marital violence in rural South India. Health Care Women Int 2005;26:87-99.

29 NIPORT MaA and ORC Macro. Bangladesh demographic and health survey 2004. Dhaka, Bangladesh and Calverton, Maryland, USA: National Institute of Population Research and Training, Mitra and Associates, and ORC Macro, 2005.

30 Rothman KJ, Greenland S. Modern epidemiology. Philadelphia, PA: LippincottRaven, 1998.

31 Garcia-Moreno C, Watts C. Violence against women: its importance for HIV/ AIDS. Aids 2000;14(Suppl 3):S253-265.

32 Martin SL, Curtis S. Gender-based violence and HIV/AIDS: recognizing links and acting on evidence. Lancet 2004;363:1410-11.

33 Heyward WL, Batter VL, Malulu M, et al. Impact of HIV counseling and testing among child-bearing women in Kinshasa, Zaire. AIDS 1993;7:1633-7.

34 Keogh P, Allen S, Almedal C, et al. The social impact of HIV infection on women in Kigali, Rwanda: a prospective study. Soc Sci Med 1994;38:1047-53.

35 Maman S, Mbwambo J, Hogan NM, et al. Women's barriers to HIV-1 testing and disclosure: challenges for HIV-1 voluntary counseling and testing. AIDS Care 2001;13:595-603.

36 Medley A, Garcia-Moreno C, McGill S, et al. Rates, barriers and outcomes of HIV serostatus disclosure among women in developing countries: implications for prevention of mother-to-child transmission programmes. Bull World Health Organ 2004;82:299-307.

37 Mayaud P, Mabey D. Approaches to the control of sexually transmitted infections in developing countries: old problems and modern challenges. Sex Transm Infect 2004;80:174-82. 